\title{
CLONAGEM E EXPRESSÃO DA PORÇÃO ENZIMÁTICA DA QUITINA SINTASE DE Moniliophthora perniciosa (STAHEL) AIME \& PHILLIPS-MORA A PARTIR DE CÉLULAS DE Escherichia coli
}

\author{
Raquel Benevides; Edjane Bastos; Afonso_Menezes \\ 1. Bolsista PROBIC/UEFS, Graduando em Licenciatura em Ciências Biológicas, Universidade Estadual de Feira de Santana, \\ e-mail: netonascto35@gmail.com \\ 2. Orientadora, Departamento de ciências biológicas, Universidade Estadual de Feira de Santana, e-mail: \\ raquelgb@gmail.com \\ 3. Participante do projeto, Departamento de Ciências Biológicas, Universidade Estadual de Feira de Santana, e-mail: \\ Edjanebferreira@gmail.com
}

PALAVRAS-CHAVE: vassoura de bruxa; sintase da quitina; vetor da clonagem

\section{INTRODUÇÃO}

A quitina é um homopolissacarídeo linear com uma função estrutural de extrema importância na composição das membranas celulares dos fungos. Sendo um desses o Moniliophtora perniciosa, causador da fitopatologia da cultura do Theobroma cacao, a Vassoura-de-bruxa, que infecta as regiões meristemáticas da planta, especialmente frutos novos, lançamentos e almofadas florais, causando queda acentuada na produção, dano nas almofadas florais e causando enfraquecimento da planta (Brasil, 2013). Com os conhecimentos adquiridos a partir da descoberta da sequência do genoma do Moniliophtora perniciosa por Souza (2012), foram criadas alternativas para o controle do fungo nas plantações de cacau, onde a inibição ou desregulação das principais enzimas são objetivos importantes para o desenvolvimento de fungicidas (Merzendorfer, 2003). No qual, este presente trabalho se baseia no pressuposto da elaboração de um inibidor para enzimas da rota de síntese da quitina, como a Quitina Sintase, dispondo-se a fazer a clonagem da porção enzimática da Quitina Sintase que proporcionará testes in vitro de possíveis inibidores para controle do Moniliophtora perniciosa.

\section{MATERIAL E MÉTODOS}

O gene sintético da Quitina Sintase foi obtido a partir do trabalho de Souza (2012). Os primers foram selecionados a partir da sequência dos nucleotídeos disponíveis no GenBank sob o número EU154354.

A reação em cadeia da polimerase (PCR) foi realizada com o Kit Toptaq ${ }^{\circledR}$ MasterMix (Qiagen ${ }^{\circledR}$ ) utilizando o termociclador Mastercycler 5333 (Eppendrof®) com os primers direto e reverso contendo os sítios de restrição para as enzimas $S g f 1$ e Pme1, segundo as recomendações do fabricante. Posteriormente realizou-se uma eletroforese em gel de agarose a $1 \%$ seguindo os seguintes padrões $\mathrm{V}=96$; $\mathrm{mA} 80$; W 7; tempo $30 \mathrm{~min}$;

Subsequentemente foi realizada a purificação da amostra da PCR utilizando o kit PureLink ${ }^{\circledR}$ PCR purification Invitrogen ${ }^{\circledR}$, seguindo as recomendações do fabricante. O DNA purificado foi armazenado a $4{ }^{\circ} \mathrm{C}$ para uso imediato e posteriormente a $-20{ }^{\circ} \mathrm{C}$ para armazenamento a longo prazo.

A partir daí o incerto e o vetor amplificados foram preparados por digestão com as endonucleases de restrição (Pmel e Sgf1). A reação foi incubada por 3 horas a $37^{\circ} \mathrm{C}$, em seguida foi colocada a $80^{\circ} \mathrm{C}$ por 20 minutos para desativação das enzimas. Os componentes da reação estão representados na Tabela 1. Em seguida, foi feito uma eletroforese em gel de agarose a $1 \%$ obedecendo aos seguintes padrões $\mathrm{V}=96 ; \mathrm{W}=7 ; \mathrm{mA}=80$; Tempo $=30 \mathrm{~min}$. 
TABELA 1: digestão do inserto e do vetor $\mathrm{pF} 3 \mathrm{a}$

\begin{tabular}{l|l|l|l|}
\hline DIGESTÃO DO VETOR pF3a & \multicolumn{3}{l|}{ DIGESTÃO DO INSERTO } \\
\hline COMPONENTE & VOLUME $\mu$ l & COMPONENTE & VOLUME $\mu \mathrm{l}$ \\
\hline pF3a & 20 & Inserto Q.S & 20 \\
\hline Pme1 & 1 & Pme1 & 1 \\
\hline Sgf1 & 1 & Sgf1 & 1 \\
\hline Buffer & 5 & Buffer & 5 \\
\hline BSA & 1 & BSA & 1 \\
\hline H2O & 22 & $\mathrm{H}_{2} \mathrm{O}$ & 22 \\
\hline Total & 50 & Total & 50 \\
*inserto Q.S se refere a porção enzimática & &
\end{tabular}

*inserto Q.S se refere a porção enzimática

\section{RESULTADOS ALCANÇADOS E DISCUSSÃO}

\section{PCR do gene sintético}

O gene sintético utilizado é composto pela porção enzimática e transmembrânica da quitina sintase inserida no vetor $\mathrm{pF} 3 \mathrm{a}$, que contêm os sítios de restrição, e o gene de resistência ao antibiótico ampicilina. Para amplificação foi utilizado o Kit Toptaq ${ }^{\circledR}$ Master Mix Qiagen ${ }^{\circledR}$ com os primers direto e reverso contendo os sítios de restrição $S g f 1$ e Pme 1 . Cuja inserção na sequência a ser amplificada é torna-la compatível com as endonucleases de restrição e com a clonagem no vetor pF3a (NELSON \& COX, 2014). A sequência dos primers desenhados foram referentes a porção enzimática da Quitina Sintase (TABELA 1).

TABELA 2: Primers selecionados com suas enzimas de restrição.

\begin{tabular}{lccc}
\hline \multirow{2}{*}{ Primer } & $\begin{array}{c}\text { Enzimas de } \\
\text { restrição }\end{array}$ & Sequência & T.M* \\
& $S g f \mathrm{I}$ & GGA ATAGCG ATC GC* ATG GCG AAT CGC CCG CC & $70{ }^{\circ} \mathrm{C}$ \\
Direto & & & \\
Reverso & PmeI & GGC $\underline{\text { GTT TAA AC }}$ A ACA CCG GGC AGG TTG GGA AG & $66{ }^{\circ} \mathrm{C}$ \\
& & & \\
\hline
\end{tabular}

*temperatura de anelamento.

Demonstra-se o resultado da PCR na Figura 1, onde é possível visualizar o amplificado em torno de 1800 pb. A PCR é extremamente útil na obtenção de DNA para clonagem recombinante, uma vez que o gene ou os genes de interesse podem ser facilmente amplificados se suas sequências de interesse forem conhecidas (NELSON; COX, 2014). 
FIGURA 1: Gel de agarose a $1 \%$ obedecendo aos seguintes padrões: $\mathrm{V}=96 ; \mathrm{W}=7 ; \mathrm{mA}=80 ;$ Tempo $=30 \mathrm{~min}$

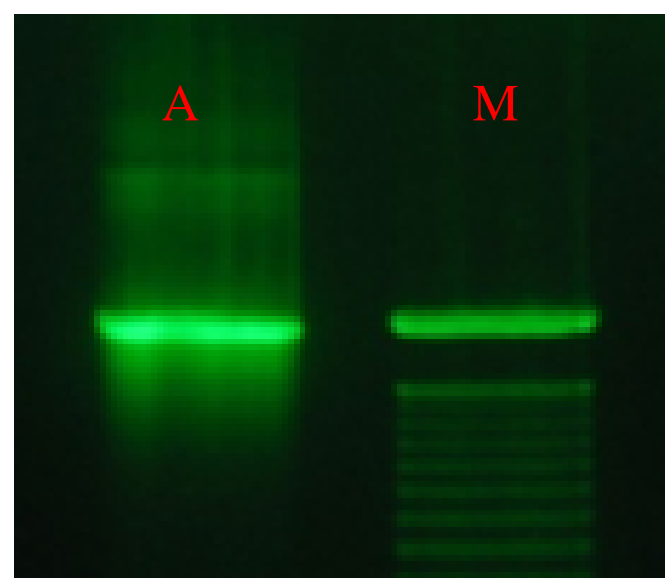

Legenda: (A) Banda com gene sintético com a sequência codificante da porção enzimática amplificada (1800pb); (M) marcador molecular 100 bp (Primeira banda 2000pb) (Invitrogen ${ }^{\circledR}$ LADDER).

\section{Digestão por endonucleases de restrição}

Após a purificação do produto da PCR, o inserto amplificado a ser clonado foi preparado por digestão com endonucleases de restrição para obter o fragmento de 1800 pares de bases, assim como o vetor pF3a. A reação apresentou boa eficiência, como se apresenta na Figura 2.

FIGURA 2: Gel de agarose a $1 \%$ obedecendo aos seguintes padrões: $\mathrm{V}=96 ; \mathrm{W}=7 ; \mathrm{mA}=80 ;$ Tempo $=30 \mathrm{~min}$

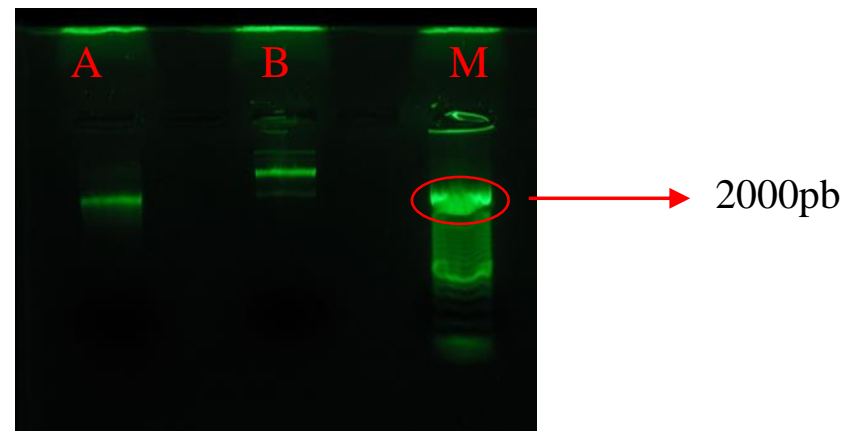

Legenda: (A) inserto após digestão; (B) plasmídeo (pF3a) após digestão; (M) marcador molecular 100 bp (Invitrogen ${ }^{\circledR}$ LADDER)

Logo em seguida foram analisadas as concentrações do inserto (porção enzimática) e plasmídeo (pF3a) no NanoDrop (Thermofisher scientific ${ }^{\circledR}$ ) (TABELA 2), os quais não apresentaram concentrações suficientes para a ligação (> $30 \mathrm{ng} / \mu \mathrm{l}$ ) e, posteriormente, a transformação em células de E. coli. Isso se justifica pois, as ligações experimentais devem conter entre $0,01 \mathrm{e} 0,1 \mu \mathrm{g}$ do inserto e diferentes quantidades do plasmídeo; sendo que as proporções devem variar de 1:4 a 8:1 (Joseph \& Russell, 2001). Em razão das baixas concentrações obtidas, não foi possível prosseguir com a ligação.

Este resultado destaca a importância do desenvolvimento de métodos otimizados para a purificação dos ácidos nucléicos submetidos a reações enzimáticas.

QUADRO 2: Análise da concentração do plasmídeo e inserto

\begin{tabular}{|c|c|}
\hline Plasmídeo & $17 \mathrm{ng} / \mu \mathrm{l}$ \\
\hline Inserto & $12 \mathrm{ng} / \mu \mathrm{l}$ \\
\hline
\end{tabular}




\section{CONCLUSÕES}

A partir dos resultados alcançados, foi possível amplificar a região de interesse com boa concentração e efetuar a restrição enzimática do gene sintético com sucesso. Porém, devido à baixa concentração da recuperação da amostra após digestão, a continuação da pesquisa foi inviabilizada. Para recuperar o purificado em maior concentração após a digestão, sugere-se realizar a diluição final em menor volume, obtendo-se assim um purificado em concentração suficiente para proceder ao passo de clonagem e transformação em E. coli e assim viabilizar os experimentos de expressão heteróloga.

\section{REFERÊNCIAS}

NELSON, D. L.; COX, M. M. Princípios de bioquímica de Lehninger. 6 ed. Porto Alegre:Artmed, 2014.

BRASIL. Ceplac. Comissão Executiva do Plano da Lavoura Cacaueira. Cacau. Disponível em: <http://www.ceplac.gov.br/radar/cacau.htm>. Acesso em: 08 ago. 2018

MERZENDORFER, H.; ZIMOCH, L. Chitin metabolism in insects: structure, function and regulation of chitin synthases and chitinases. Journal of Experimental Biology, v. 206, n. 24, p. 4393-4412, 2003. 